\title{
Design of a Bidirectional Antenna inside a Vehicle and Measurement of Power Link for Vehicle-to-Vehicle Communication at $5.8 \mathrm{GHz}$
}

\author{
Soon-Soo Oh $\mathbb{D}^{1},{ }^{1}$ Dong-Woo Kim, ${ }^{1}$ Se-Woong Na, ${ }^{2}$ Jin-Dae Kim, ${ }^{2}$ and Wook-Ki Park ${ }^{3}{ }^{3}$ \\ ${ }^{1}$ Department of Electrical Engineering, Chosun University, 309 Pilmun-daero, Dong-gu, Gwangju 61452, Republic of Korea \\ ${ }^{2}$ Carnavi.com Co. Ltd., 1190 Gyeongwon-daero, Bupyeong-gu, Incheon 21440, Republic of Korea \\ ${ }^{3}$ Future Industry Technology Center, IBITP, 12 Gaetbeol-ro, Yeonsu-gu, Incheon 21999, Republic of Korea
}

Correspondence should be addressed to Wook-Ki Park; wkpark@ibitp.or.kr

Received 30 June 2017; Accepted 28 March 2018; Published 26 April 2018

Academic Editor: Symeon Nikolaou

Copyright (C) 2018 Soon-Soo Oh et al. This is an open access article distributed under the Creative Commons Attribution License, which permits unrestricted use, distribution, and reproduction in any medium, provided the original work is properly cited.

Communication between moving vehicles is very important for safety. In this paper, a bidirectional antenna that can be installed inside a vehicle is proposed and tested in a real vehicular environment at $5.8 \mathrm{GHz}$. The forward link and backward link seated by two persons and three persons were compared in terms of received RF power and the peak-to-average power ratio (PAR). It was found that, even with three persons, the power link fulfilled the communication requirements using the proposed antenna.

\section{Introduction}

Currently, road traffic is becoming heavier, so that intelligent communication between moving vehicles is very important [1]. Vehicle-to-vehicle (V2V) communication for IEEE 802.11p Wireless Access in Vehicular Environments (WAVE) has been achieved by antennas installed on the roofs of vehicles [2-4]. Installation of the antenna should cut part of the roof of the vehicle. In this paper, an antenna that can be installed inside a vehicle is proposed for WAVE communication operating at $5.8 \mathrm{GHz}$. Experiments on a power link between two vehicles are also done. Forward and backward links are compared, and the backward link seated by two persons and three persons is described.

\section{Antenna Design}

Figure 1 shows the structure of the proposed bidirectional array antenna. The designed frequency is $5.8 \mathrm{GHz}$. Figure 1(a) shows a transparent view of a single radiation patch: the single-layer substrate has a dielectric constant of 2.2 , loss tangent of 0.0009 , and thickness of $0.508 \mathrm{~mm}$. The patch is denoted by green shading and has a size of $15 \mathrm{~mm} \times 15 \mathrm{~mm}$. The hatched rectangular box is the ground positioned on the other side of the patch. The feeding port is positioned at the end of the microstrip line. Figure 1(b) shows an array with two patches. The interelement spacing is $24.5 \mathrm{~mm}$. Figure 1 (c) shows an array with three patches and a power divider that is closer to a port and has a $1: 2$ power ratio. The single patch shown in Figure 1(a) is similar to a previous model [5], but the array models in Figures 1(b) and 1 (c) have not been reported previously to the best of our knowledge, even though they can be easily configured [6]. The radiation pattern of the proposed array antenna is expected to be bidirectional, since the ground plane behind the radiation patch is etched.

A simulation was performed using the commercial software ANSYS Designer. Figure 2 illustrates the current distribution for each antennas at their resonant frequencies. The currents on the patches flow in the feeding direction and distribute on patches equally. The optimized antenna was fabricated with an etching process, as shown in Figure 3(a), and the reflection coefficient was measured for three kinds of antenna. The reflection coefficient $\left(S_{11}\right)$ was 


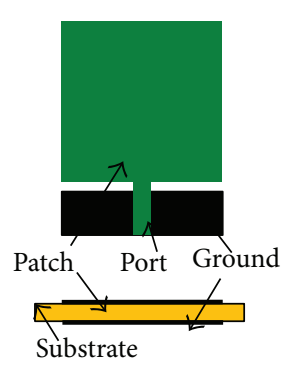

(a)

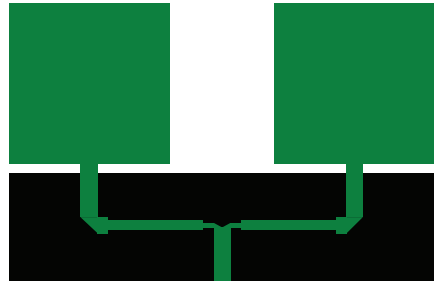

(b)

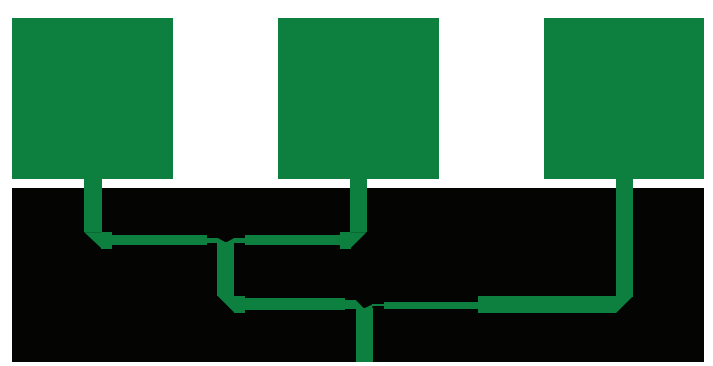

(c)

FIGURE 1: Structure of the proposed bidirectional antenna: (a) single radiation patch; (b) two patches; (c) three patches.

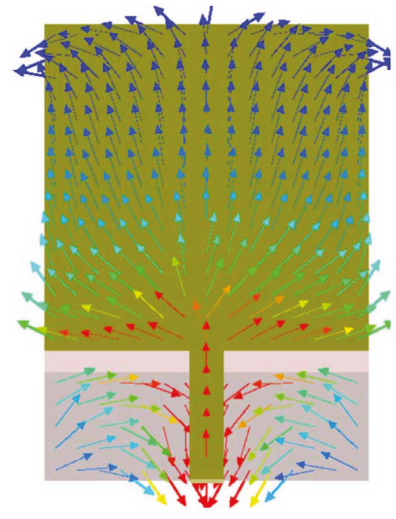

(a)

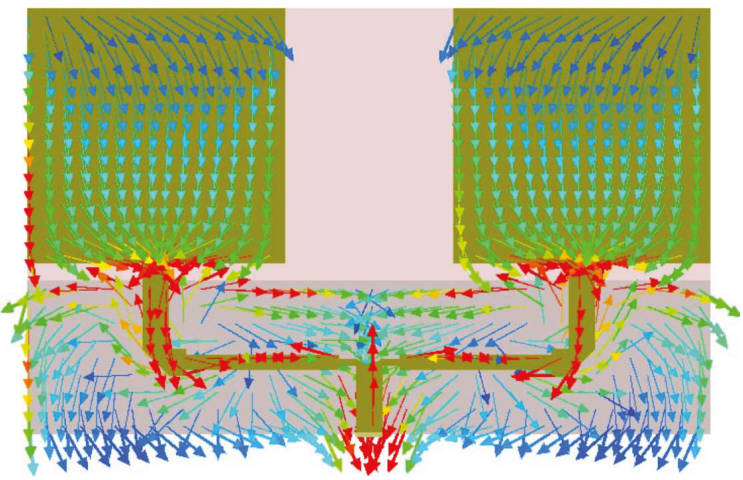

(b)

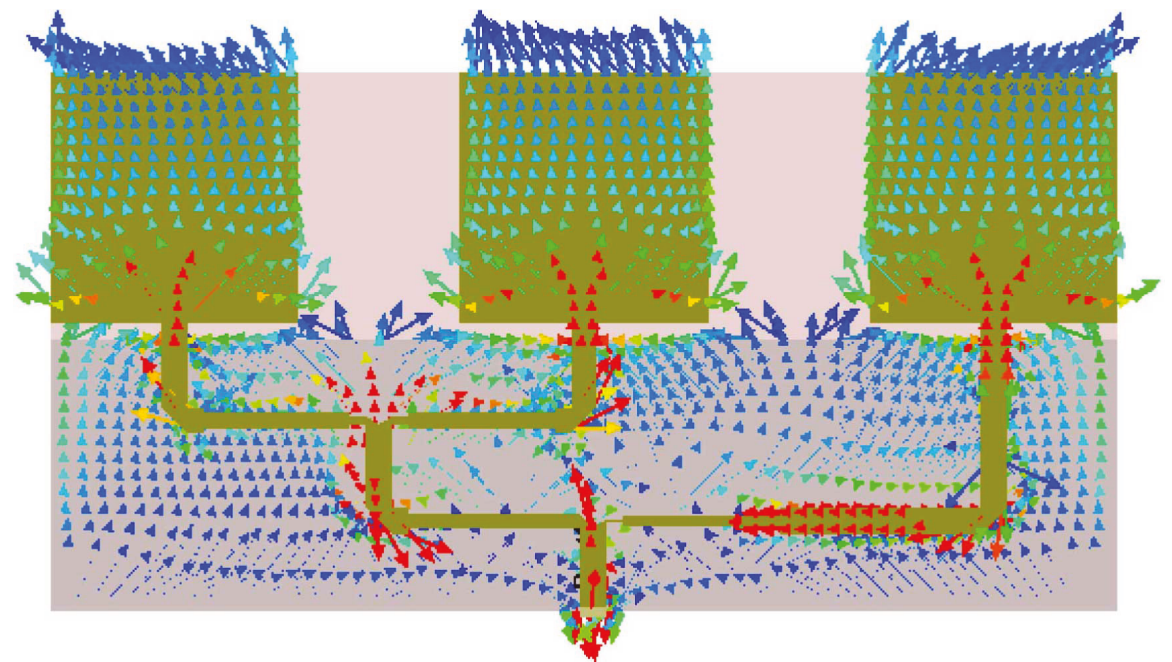

(c)

Figure 2: The current distribution of the proposed antenna: (a) single radiation patch; (b) two patches; (c) three patches.

below $-10 \mathrm{~dB}$ for the measurement as shown in Figure 3(b). The simulated and measured radiation patterns on the $\mathrm{H}$ plane are shown in Figure 4 and had very good agreement. The photograph of the fabricated antenna is inserted in the radiation pattern. The measured $3 \mathrm{~dB}$ beam width was omnidirectional, $51^{\circ}$, and $36^{\circ}$ for the one, two, and three radiation patches, respectively, and the measured gain was 2.70, 5.78, and $6.62 \mathrm{dBi}$, respectively. As shown in Figure 4, the array antennas with two and three patches are bidirectional, and they are more directive compared with the singlepatch antenna.

\section{Measurement of Path Loss and PAR}

To test the ability of wireless communication between vehicles, the received power was measured. Figure 5 shows the antenna installation and experimental setup. The transmitting $(\mathrm{Tx})$ antenna connected to the signal generator (SG) 


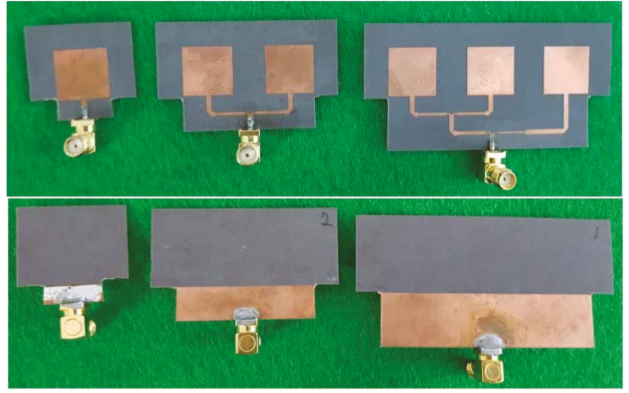

(a)

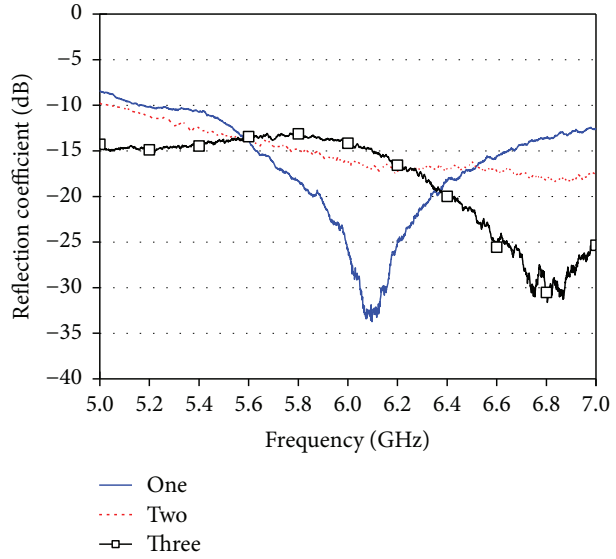

(b)

FIgURE 3: The fabricated antenna: (a) photograph; (b) the reflection coefficient $\left(\mathrm{S}_{11}\right)$.

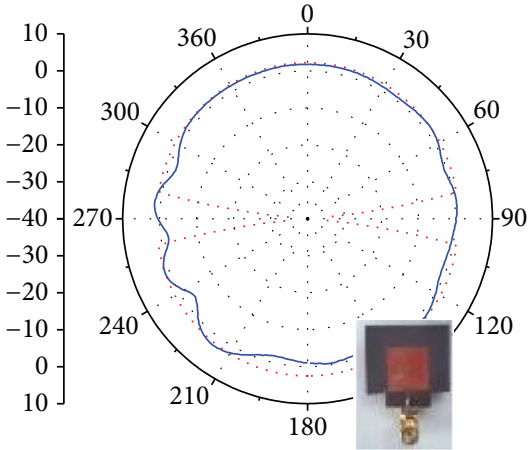

… Simulate

— Measured

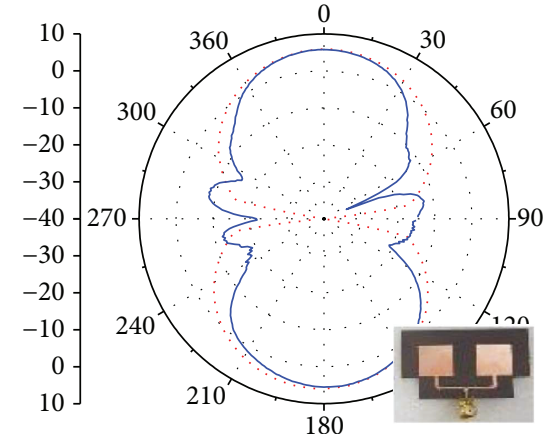

$\begin{array}{ll}\ldots \text { Simulated } \\ - & \text { Measured }\end{array}$

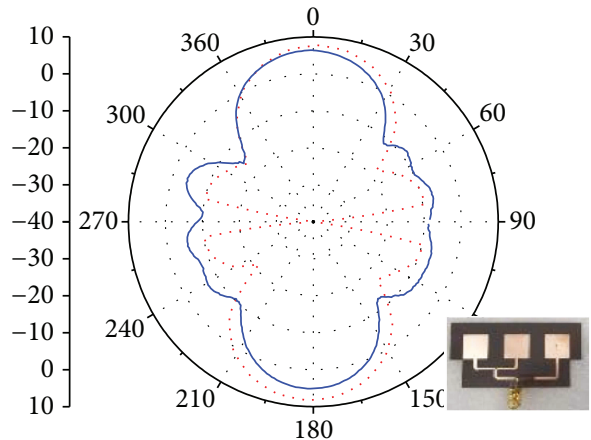

.... Simulated

- Measured

(a)

(b)

(c)

FIGURE 4: Simulated and measured H-plane radiation patterns of the bidirectional antennas at $5.8 \mathrm{GHz}$ : (a) single radiation patch; (b) two patches; (c) three patches.
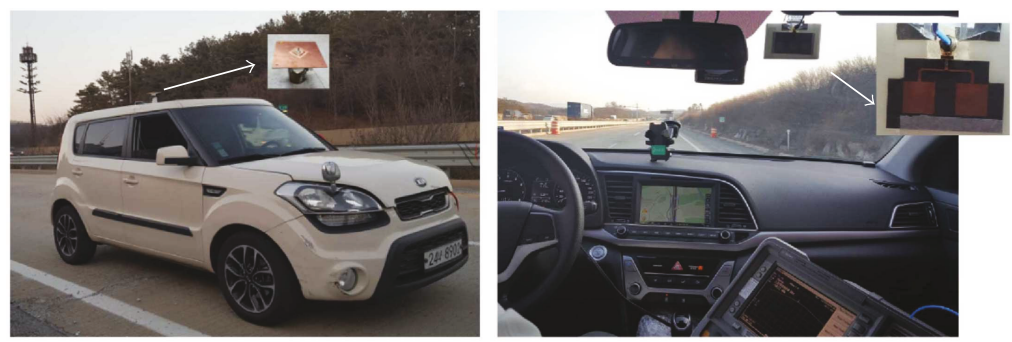

(a)

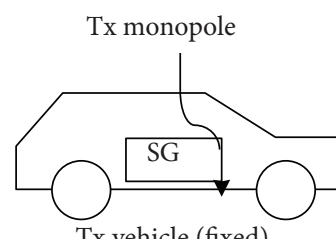

Tx vehicle (fixed)

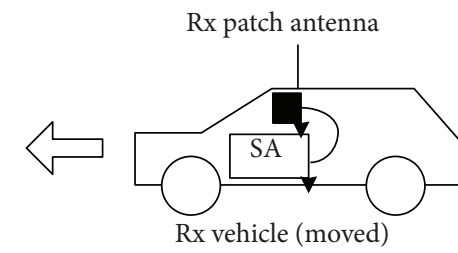

(b)

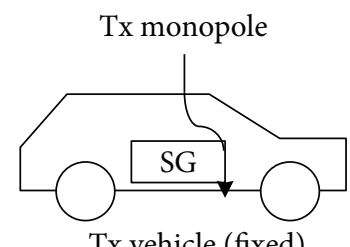

Tx vehicle (fixed)
Rx patch antenna

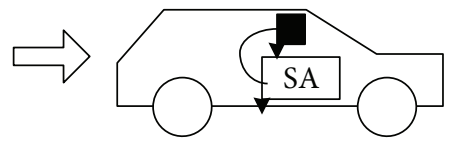

Rx vehicle (moved)

(c)

FIGURE 5: Experimental setup for vehicle-to-vehicle (V2V) communication at $5.8 \mathrm{GHz}$ (a) transmitting (Tx) vehicle (left) and receiving (Rx) vehicle (right); (b) forward link; (c) backward link. 


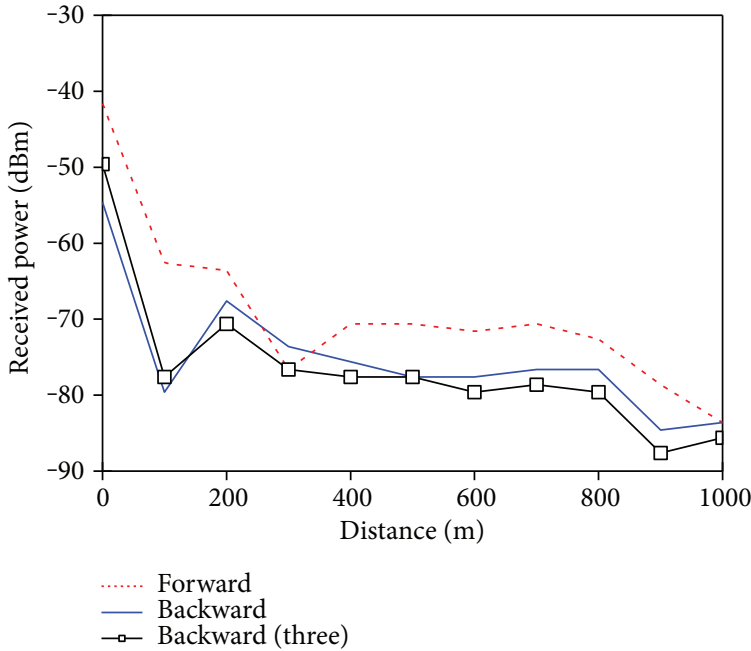

(a)

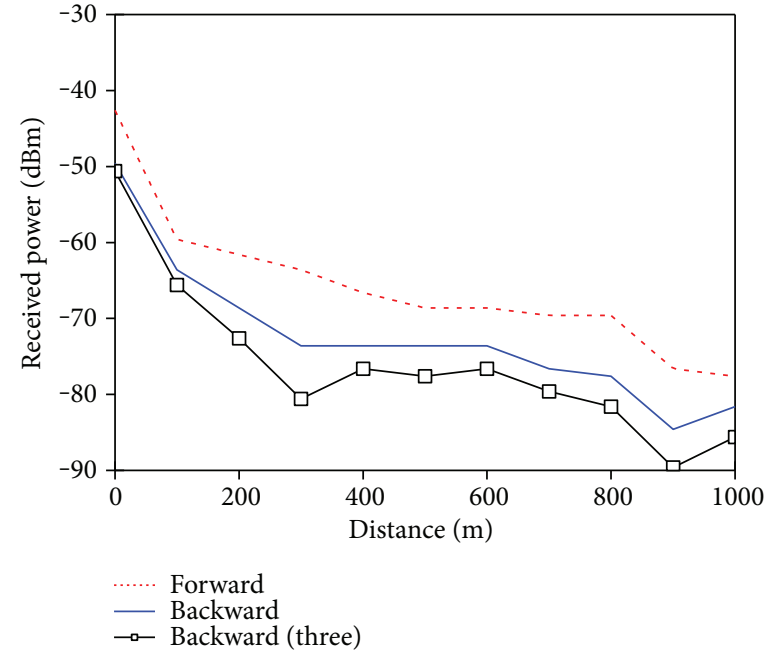

(b)

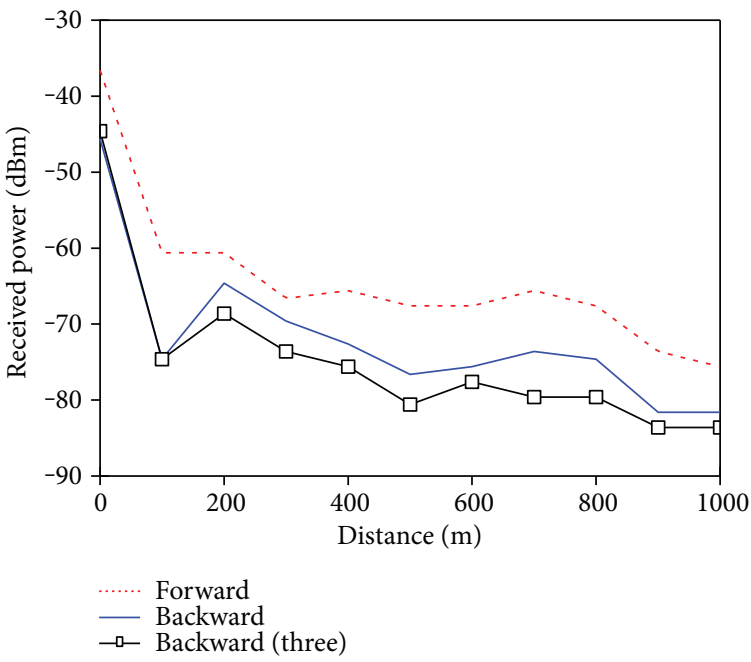

(c)

Figure 6: Measured received power for V2V communication at $5.8 \mathrm{GHz}$ : (a) single radiation patch; (b) two patches; (c) three patches.

with a continuous wave (CW) RF output signal of $20 \mathrm{dBm}$ is loaded on top of the static vehicle, as shown in Figure 5(a). The type of the Tx antenna is a monopole antenna with an $\mathrm{H}$-plane gain of $1.05 \mathrm{dBi}$. The receiving $(\mathrm{Rx})$ antenna connected to the spectrum analyzer (SA) is positioned near the front window inside the moving vehicle as shown in the right figure of Figure 5(a). Forward communication occurs when two vehicles face each other, so that the communication is done via the front window. Meanwhile, backward communication occurs when two vehicles are positioned in the same direction, so that the communication is done via the rear window. It should be noted that forward propagation only has the front window as the obstacle. Meanwhile, backward propagation has several obstacles, such as the interior conductor, seat, rear window, and human body. In particular, the effect of the human body should not be neglected.

Figure 6 shows the received power for the experiment shown in Figure 5. Cable loss is extracted from the received power. As shown in Figure 6(c), the received power increases with an increasing number of radiation patches.
It should be noted that, as shown in Figure 6, the received power for the forward direction is higher than the minimum receiver sensitivity of $-95 \mathrm{dBm}$. Another interesting aspect is that the received power for the backward direction is lower than that for the forward direction, by about 5 to $10 \mathrm{~dB}$. This might be due to absorption by the human body and car seat inside the vehicle and due to reflection from the interior of the vehicle.

For verification of the effect of the human body, one more experiment was performed in the backward direction for three persons instead of two persons. As a result, the received power decreased by about $3 \mathrm{~dB}$. In the investigation shown in Figure 6, however, the received power for the backward direction, even in the three-person scenario, is still higher than that for the minimum receiver sensitivity.

To test the digital communication function, the peak-toaverage power ratio (PAR) was measured for the orthogonal frequency division multiplexed- (OFDM-) modulated signal based on IEEE 802.11p [2]. As expected from Figure 6, the forward link shows higher PAR. The backward link for the 


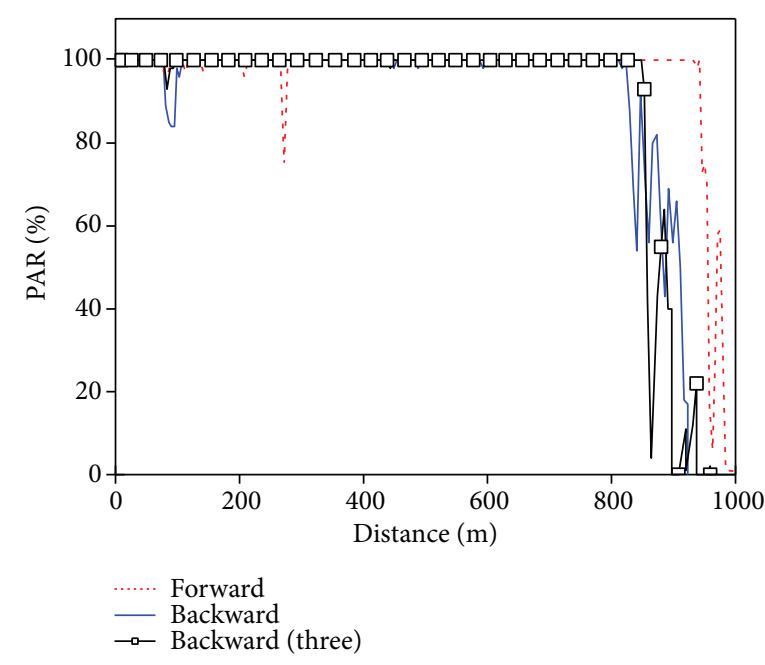

(a)

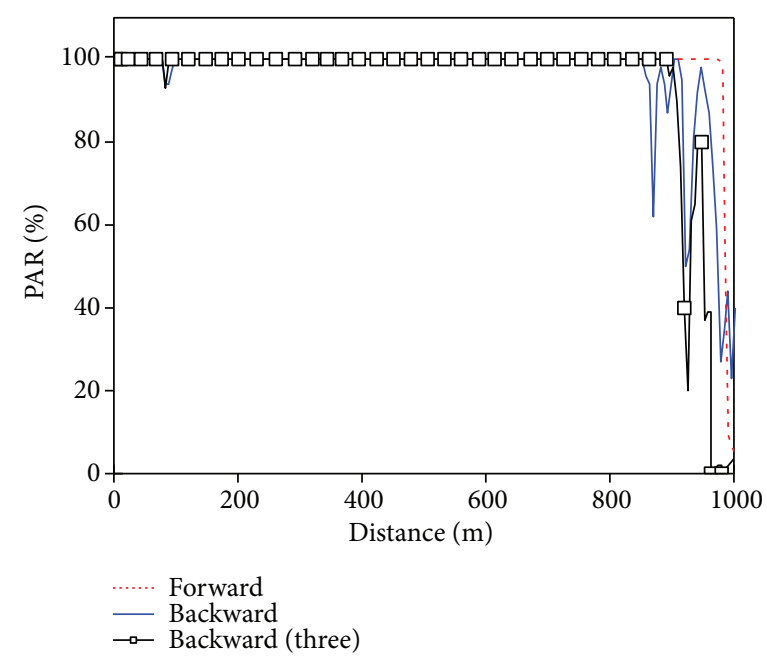

(b)

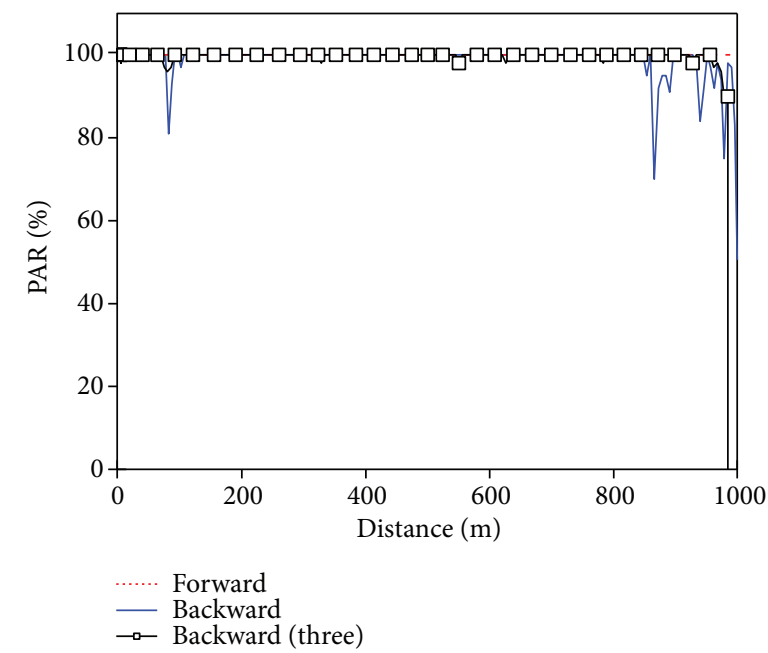

(c)

Figure 7: Measured PAR for V2V communication at $5.8 \mathrm{GHz}$ : (a) single radiation patch; (b) two patches; (c) three patches.

two-person scenario has better PAR than the scenario with three persons, as shown in Figures $7(\mathrm{a})-7(\mathrm{c})$, so that the available distance is longer. Backward communication for the three-person scenario with a single patch is possible up to about $800 \mathrm{~m}$, as shown in Figure 7(a), whereas the distance for three patches is about $950 \mathrm{~m}$.

\section{Conclusion}

In this paper, a bidirectional antenna installed inside a vehicle was proposed and the experimental results of a power link between two vehicles described. A single radiation patch antenna and array antenna were designed and fabricated. The received power and PAR were measured in a real vehicular environment. Backward link performance for the threeperson scenario was also tested. As a result, the array antenna showed better performance than the single-patch antenna. The value of the backward link is deteriorated versus that of the forward link. However, even for three-person scenario, the backward link still showed greater received power and PAR than the required value. From these results, the proposed antenna could be utilized for $\mathrm{V} 2 \mathrm{~V}$ communication when installed inside a vehicle.

\section{Conflicts of Interest}

The authors declare that there is no conflict of interest regarding the publication of this paper.

\section{Acknowledgments}

This research was supported by Grant 1615009062 from the Transportation and Logistics Research Program funded by the Ministry of Land, Infrastructure and Transport of the Korean Government, and this research was supported by a research fund from Chosun University in Korea, 2017.

\section{References}

[1] Q. Yang and H. Wang, "Toward trustworthy vehicular social networks," IEEE Communications Magazine, vol. 53, no. 8, pp. 42-47, 2015. 
[2] IEEE Vehicular Technology Society, IEEE Standard for Wireless Access in Vehicular Environments (WAVE), IEEE Std 1609.4, IEEE (The Institute of Electrical and Electronics Engineers, Inc), New York, NY, USA, 2016.

[3] N. Adhikari, A. Kumar, and S. Noghanian, "Multiple antenna channel measurements for car-to-car communication," IEEE Antennas and Wireless Propagation Letters, vol. 15, pp. 674677, 2016.

[4] M. Nilsson, P. Hallbjorner, N. Araback, B. Bergqvist, and F. Tufvesson, "Multipath propagation simulator for V2X communication tests on cars," in 2013 7th European Conference on Antennas and Propagation (EuCAP), Gothenburg, Sweden, April 2013.

[5] K. Y. Mok, Y. C. Rhee, and J. H. Yoon, "Design of a pot-shaped monopole antenna with dual band notched characteristics for UWB application," Journal of Electromagnetic Engineering and Science, vol. 17, no. 1, pp. 44-49, 2017.

[6] W. L. Stutzman and G. A. Thiele, Antenna Theory and Design, John Wiley \& Sons, Hoboken, New Jersey, 1998. 


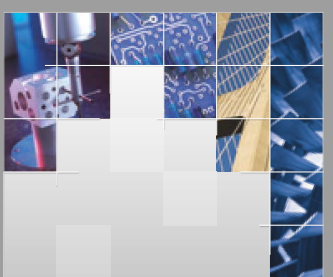

\section{Enfincering}
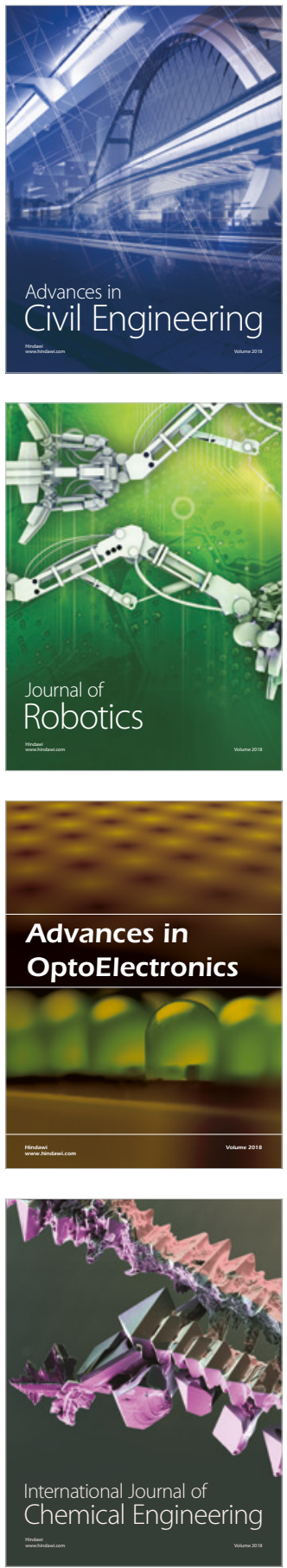

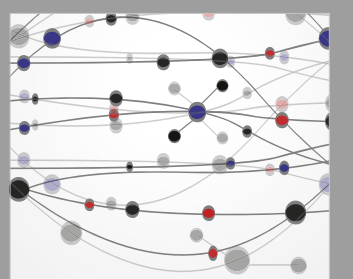

\section{Rotating \\ Machinery}

The Scientific World Journal

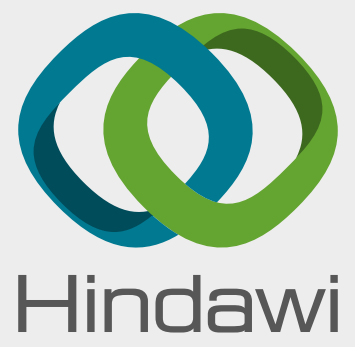

Submit your manuscripts at

www.hindawi.com
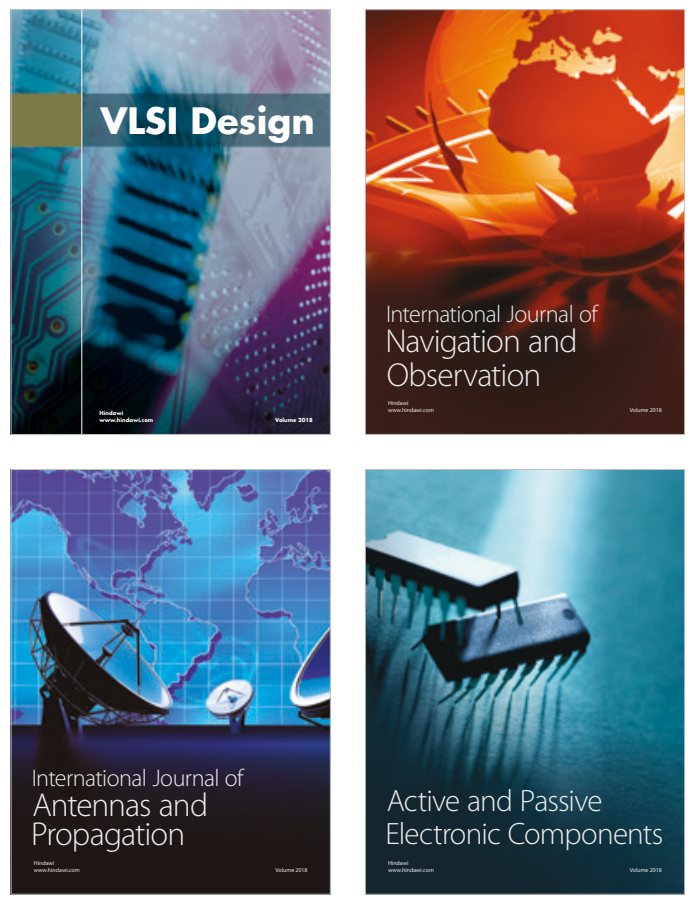
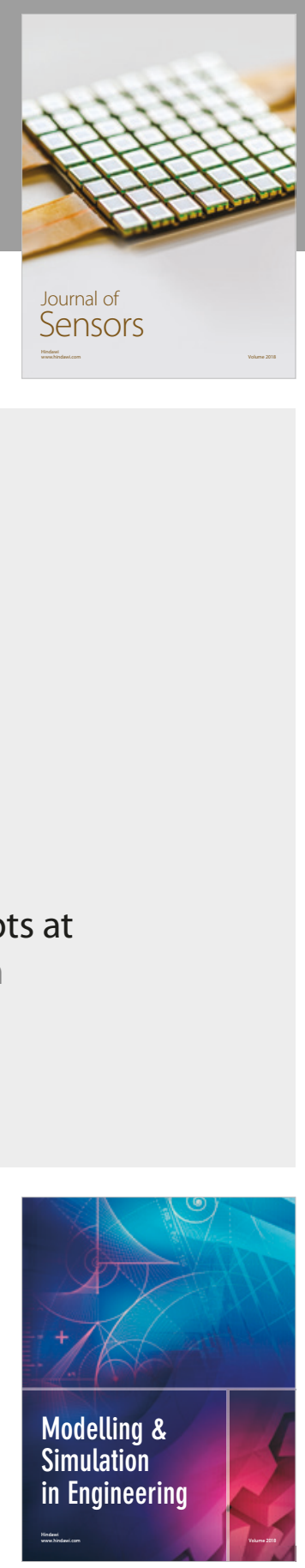

\section{Advances \\ Multimedia}
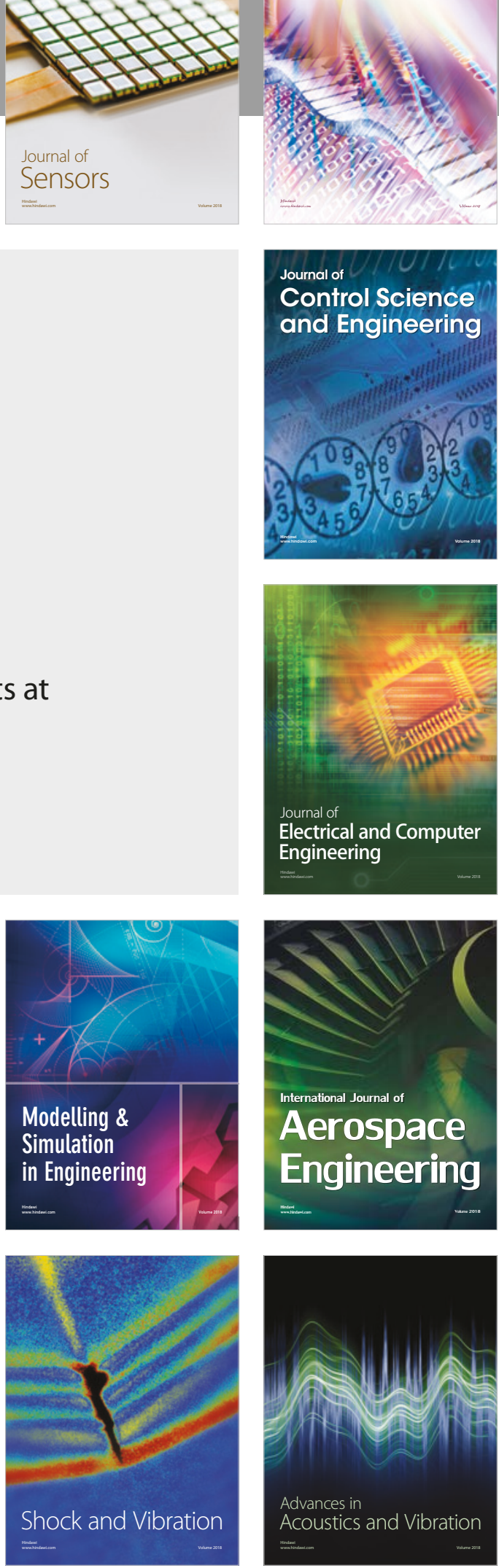